\title{
Nonlinear Control of a Satellite Electrical Power System Based on the Sliding Mode Control
}

\author{
Mohammad Rasool Mojallizadeh ${ }^{1}$ and Bahram Karimi ${ }^{2}$ \\ ${ }^{1}$ Department of Electrical Engineering, Najafabad Branch, Islamic Azad University, University Blvd., Najafabad, Isfahan, Iran \\ ${ }^{2}$ Department of Electrical Engineering, Malek Ashtar University of Technology, Shahinshahr, Isfahan, Iran \\ Correspondence should be addressed to Mohammad Rasool Mojallizadeh; r.mojalli@gmail.com
}

Received 26 June 2013; Accepted 22 July 2013

Academic Editors: R. V. Kruzelecky, Z. Mazur, S. Simani, and I. Taymaz

Copyright ( 2013 M. R. Mojallizadeh and B. Karimi. This is an open access article distributed under the Creative Commons Attribution License, which permits unrestricted use, distribution, and reproduction in any medium, provided the original work is properly cited.

\begin{abstract}
The power electronic interface between a satellite electrical power system (EPS) with a photovoltaic main source and battery storage as the secondary power source is modelled based on the state space averaging method. Subsequently, sliding mode controller is designed for maximum power point tracking of the PV array and load voltage regulation. Asymptotic stability is ensured as well. Simulation of the EPS is accomplished using MATLAB. The results show that the outputs of the EPS have good tracking response, low overshoot, short settling time, and zero steady-state error. The proposed controller is robust to environment changes and load variations. Afterwards, passivity based controller is provided to compare the results with those of sliding mode controller responses. This comparison demonstrates that the proposed system has better transient response, and unlike passivity based controller, the proposed controller does not require reference PV current for control law synthesis.
\end{abstract}

\section{Introduction}

As space missions are getting more involved, satellites systems are getting more complex in parallel. Even the size of satellites are getting smaller due to budgetary constraints, the amount of power required to run the complete system is getting bigger resulting in larger PV arrays, higher battery capacity, and a much more sophisticated electrical power system (EPS). The primary function of EPS is to supply and manage uninterrupted power to its subsystems and payloads. These subsystems include power generation subsystems such as PV arrays, power storage subsystems which are batteries with different chemical structures, power control and distribution subsystems like power converters, power distribution units, power conditioning units, and battery charging units [1].

In the present space power domain, most of the satellite power systems use PV arrays as their power core. Despite all the advantages presented by the generation of energy through PV cells, the efficiency of energy conversion is currently low; thus, it becomes necessary to use techniques to extract the maximum power from these panels, in order to achieve maximum efficiency in operation. The requirement for maximum power point tracking (MPPT) is raised by the fact that the MPP of the PV array continuously varies with temperature and illumination changes. Due to the nonlinear characteristic of the PV array and drastic changes in irradiance and temperature, design of the MPPT unit is important. Several studies have been carried out, such as sliding mode control [2], adaptive control [3], neural networks [4], PSO [5, 6], fuzzy logic [7], chaos search [8], and GA-PI [9]. There are also some works about comparing different MPPT algorithms, such as [10-12]. This study uses a sliding mode controller for the MPPT. Unlike passivity based controller which is introduced in [13], sliding mode control approach which is proposed in this paper does not require reference current for control law synthesis.

Sliding mode control (SMC) is popular to converters [14]. The application of SMC to DC/DC converters can be traced back to 1983 [15]. The SMC design theory and application examples are available in [16]. SMC offers several benefits, namely, large signal stability, robustness, good dynamic response, system order reduction, and simple implementation [17]. A typical sliding mode control has two modes of operation. One is called the approaching mode, where 


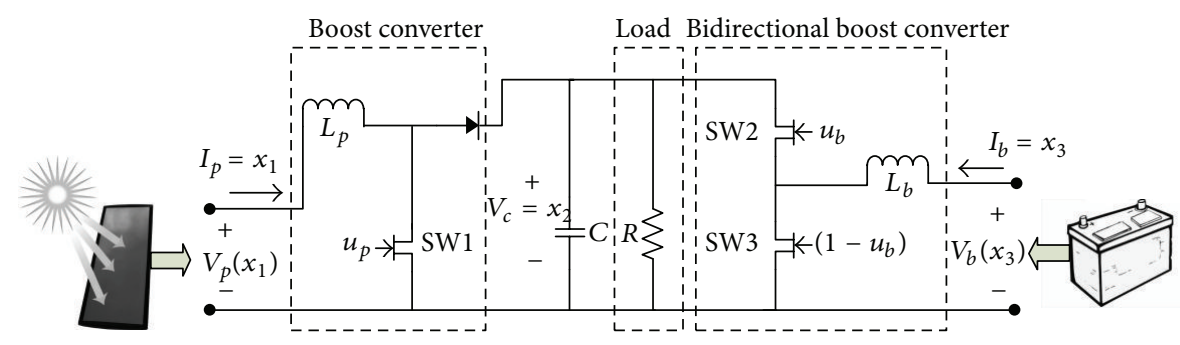

Figure 1: Proposed system diagram.

the system state converges to a predefined manifold named sliding function in finite time. The other mode is called the sliding mode, where the system state is confined on the sliding surface and is driven to the origin [16].

Passivity based control (PBC) was introduced by Ortega et al. [18], as a controller design methodology that achieves stabilization by passivation. Two theories for $\mathrm{PBC}$ have been developed: Euler Lagrange (EL)-PBC and interconnection and damping assignment (IDA)-PBC [13]. In this paper, EL$\mathrm{PBC}[13]$ is provided to compare the results with those of the proposed sliding mode controller responses.

In this study, SMC approach is used for maximum power point tracking of the PV array, load voltage regulating, and charging or discharging the battery. Asymptotic stability of the proposed system is confirmed by using Lyapunov theory.

The paper is organized as follows. System modeling is introduced in Section 2. In Section 3, design and analysis of the SMC are presented. PBC is provided in Section 4 for comparison with the proposed control approach. Simulation results in MATLAB environment are then used in Section 5 to demonstrate the effectiveness of the proposed controller. Finally, Section 6 concludes the paper.

\section{System Modeling}

The proposed satellite EPS is depicted in Figure 1. This EPS comprises a PV array, a battery storage, DC/DC converters, and load. The battery storage has been considered for conditions in which the load power exceeds the generating power of the PV array.

2.1. Photovoltaic Energy System. A solar cell is the fundamental component of a PV system, which converts the solar energy into electrical energy. A PV cell consists of a p$n$ junction semiconductor material. A PV array consists of a certain number of PV cells connected in series/parallel to provide the desired voltage and current. The equivalent circuit of a PV cell is depicted in Figure 2.

The equivalent circuit mainly consists of a current source $\left(i_{\mathrm{ph}}\right)$, in which its amplitude depends on irradiance and temperature, diode, and internal resistance $\left(r_{p}^{\prime}\right)$. The P-I characteristic of a PV cell is highly nonlinear and is given by the following equations [3]:

$$
V_{p}=\left(\frac{k_{b} T A}{q}\right) \ln \left(\frac{\left(i_{\mathrm{ph}}+i_{0}-I_{p}\right)}{i_{0}}\right)-I_{p} r_{p},
$$

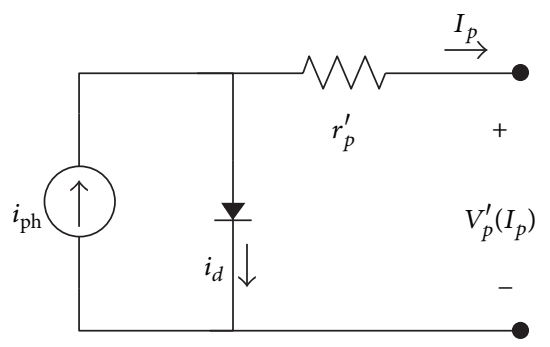

Figure 2: Equivalent circuit of the PV cell.

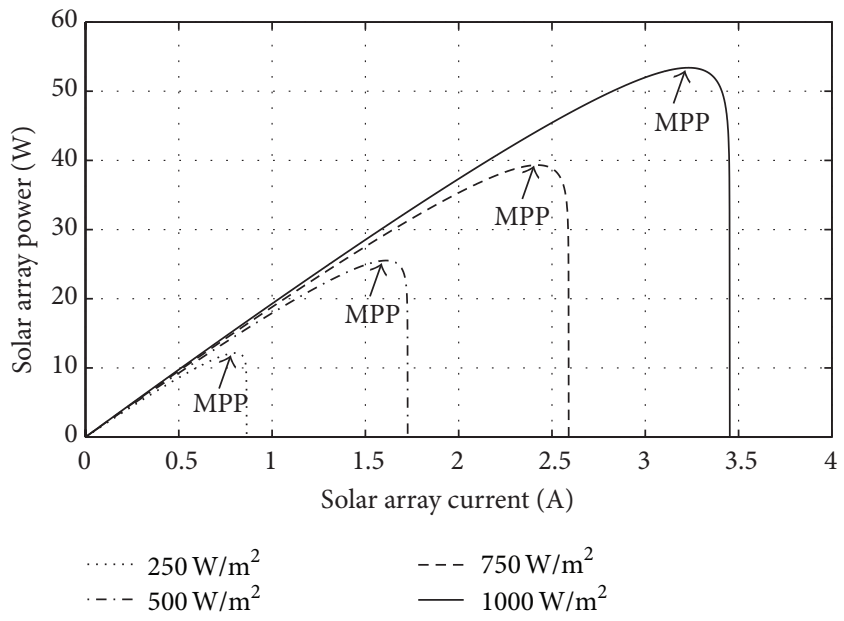

FiguRE 3: PV array characteristic under different irradiance levels.

$$
\begin{gathered}
i_{\mathrm{ph}}=\lambda\left[i_{\mathrm{sc}}+k_{i}\left(T-T_{r}\right)\right], \\
i_{0}=i_{r}\left[\frac{T}{T_{r}}\right]^{3} \exp \left(\left(\frac{q E_{g}}{\left(k_{b} A\right)}\right)\left(\frac{1}{T_{r}}-\frac{1}{T}\right)\right),
\end{gathered}
$$

where $V_{p}$ and $I_{p}$ are the PV cell voltage and current, respectively, $i_{0}$ is the diode reverse saturation current, $q$ is the electron charge, $A$ is the ideality factor of the $\mathrm{p}-\mathrm{n}$ junction, $k_{b}$ is the Boltzmann constant, $k_{i}$ is the temperature coefficient, $T$ is the cell temperature, $T_{r}$ is the reference temperature, $E_{g}$ is the bandgap energy, $i_{r}$ is the saturation current at $T_{r}$, and $i_{\mathrm{sc}}$ is the short circuit current.

Figure 3 shows the P-I curve of the SM-55 PV array under different irradiance conditions $\left(T=300^{k}\right)$. The power delivered by the PV module depends on the PV irradiance and cell temperature. Thus, maximum power must 


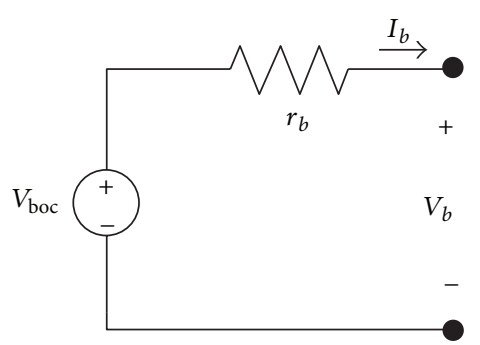

FIGURE 4: Equivalent circuit of the battery storage.

be available under different conditions. The typical approach used to maximize the power drawn from PV arrays under varying atmospheric conditions is the MPPT algorithm, which provides a reference voltage or current for the DC/DC converter. Unlike common approaches [13], in this study, the maximum power is drawn from PV array by implementing the sliding mode controller, and no desired PV reference is required.

2.2. Battery Storage. Storage devices are utilized for energy storage in EPS. The batteries store energy in the electrochemical form. In this study, the battery is modelled based on the generic Thevenin model [19]. Figure 4 shows equivalent circuit of the battery, where $V_{\text {boc }}$ is the open circuit voltage and $r_{b}$ is the equivalent resistance.

2.3. DC/DC Converters. The amplitude of the DC output current (voltage) of the PV array depending on the solar irradiance delivered to the PV arrays. Therefore, a boost $\mathrm{DC} / \mathrm{DC}$ converter is utilized to adjust the output current of the PV system. Also, a bidirectional DC/DC converter is used for load voltage regulation and charge or discharge the battery storage. The DC/DC converters have been depicted in Figure 1.

From Figure 5, the system can be written in four sets of state equation depends on the position of switches SW1, SW2, and SW3. By utilizing state space averaging method [20], dynamic equations of the system can be expressed as:

$$
\begin{gathered}
\dot{x}_{1}=\frac{\left(V_{p}\left(x_{1}\right)-x_{2}+x_{2} u_{p}\right)}{L_{p}}, \\
\dot{x}_{2}=\frac{\left(-(1 / R) x_{2}+x_{1}-x_{1} u_{p}+x_{3} u_{b}\right)}{C}, \\
\dot{x}_{3}=\frac{\left(V_{b}-x_{2} u_{b}\right)}{L_{b}},
\end{gathered}
$$

where $\mathbf{x}=\left[x_{1}, x_{2}, x_{3}\right]^{T}=\left[i_{L_{p}}, v_{C}, i_{L_{b}}\right]^{T}$ is the state vector, $0<u_{p}<1$ is the duty cycle of SW1 which is also a control input for MPPT, and $0<u_{b}<1$ is the duty cycle of SW2 which is also a control input for regulating load voltage and charging or discharging battery. Equation (3) can be written in general form of the nonlinear time invariant system:

$$
\dot{\mathbf{x}}=f(\mathbf{x})+g(\mathbf{x}) \mathbf{u} .
$$

\section{Sliding Mode Controller Design}

In the proposed EPS, the main objectives are maximum power point tracking of the PV array and load voltage regulation. In this study, an MIMO sliding mode controller is designed for these purposes. The proposed controller produces two control signals. The first control signal $\left(u_{p}\right)$ is applied to the boost converter for the MPPT of the PV array, and the second control signal $\left(u_{b}\right)$ is applied to the bidirectional boost converter for load voltage regulation. Unlike other approaches [13], in this study, no desired PV reference required for control law synthesis. Thus, the proposed system is robust to operation conditions and PV array's parameter changes.

Figure 3 shows P-I curve of the PV array under uniform insolation conditions. By selecting the PV sliding surface as (5), it is guaranteed that the system state will hit the surface and produce maximum power persistently:

$$
\frac{\partial P_{P}}{\partial I_{P}}=\frac{\partial\left(I_{P}^{2} R_{P}\right)}{\partial I_{P}}=I_{P}\left(2 R_{P}+I_{P} \frac{\partial R_{P}}{\partial I_{P}}\right)=0
$$

where $R_{p}=V_{p} / I_{p}$ is the equivalent load. The nontrivial solution of (5) selected as PV sliding surface $\left(s_{p}\right)$ :

$$
s_{p} \triangleq 2 R_{P}+I_{P} \frac{\partial R_{P}}{\partial I_{P}}
$$

With $R_{p}=V_{p} / I_{p}$, (6) can also be written as:

$$
s_{p} \triangleq 2 \frac{V_{p}\left(x_{1}\right)}{x_{1}}+x_{1} \frac{\partial\left(V_{p}\left(x_{1}\right) / x_{1}\right)}{\partial x_{1}} .
$$

Voltage regulation sliding surface $\left(s_{b}\right)$ is also selected as:

$$
s_{b}=x_{3}-x_{3 d},
$$

where $x_{3 d}$ is the desired battery current and can be described by:

$$
P_{b}=P_{L}-P_{p} \longrightarrow x_{3 d}=\frac{1}{V_{b}}\left(\frac{1}{R} x_{2 d}^{2}-V_{p} x_{1}\right)
$$

where $P_{b}, P_{L}$, and $P_{p}$ are battery, load, and PV powers respectively. By considering the sliding surface vector as (10) it is guaranteed that the system will reach its desired states:

$$
\mathbf{s}=\left[\begin{array}{l}
s_{p} \\
s_{b}
\end{array}\right]=\left[\begin{array}{c}
2 \frac{v_{p}\left(x_{1}\right)}{x_{1}}+x_{1} \frac{\partial\left(v_{p}\left(x_{1}\right) / x_{1}\right)}{\partial x_{1}} \\
x_{3}-x_{3 d}
\end{array}\right] .
$$




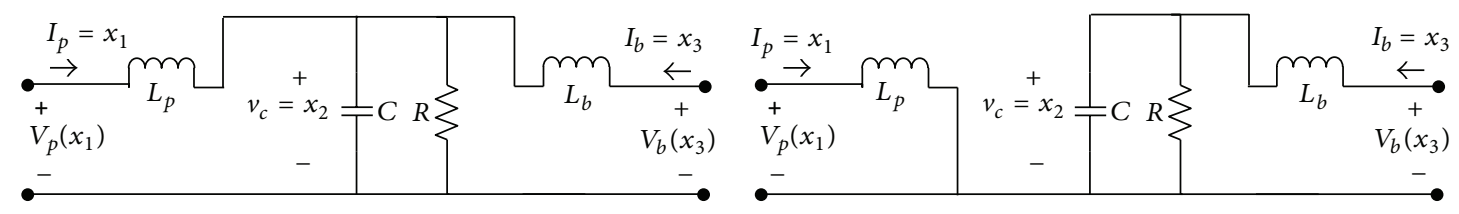

(a)

(b)

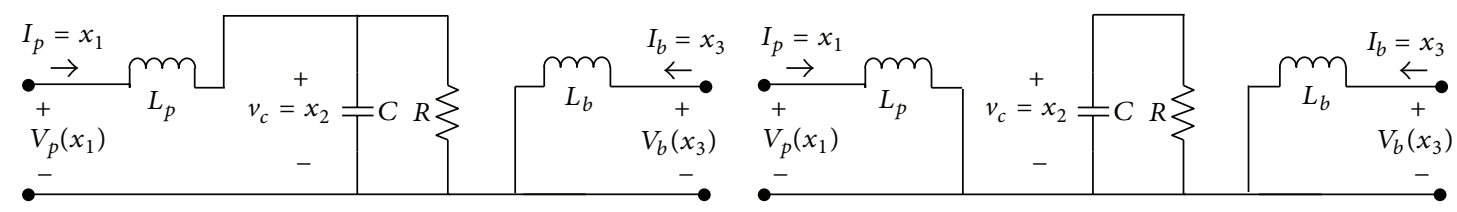

(c)

(d)

FIGURE 5: Different operating conditions. (a): SW1 = O, SW2 = C, SW3 = O. (b): SW1 = C, SW2 = C, SW3 = O. (c): SW1 = O, SW2 = O, SW3 $=$ C. $($ d $):$ SW1 $=$ C, SW2 $=$ O, SW3 $=$ C. $($ open $=\mathrm{O}$ and close $=\mathrm{C})$.

In order to get the equivalent control $\left(\mathbf{u}_{\mathrm{eq}}\right)$ suggested by [16], the equivalent control is determined from the following condition:

$$
\begin{aligned}
\dot{\mathbf{s}} & =\left[\begin{array}{l}
\frac{\partial s_{p}}{\partial x_{1}} \dot{x}_{1}+\frac{\partial s_{p}}{\partial x_{2}} \dot{x}_{2}+\frac{\partial s_{p}}{\partial x_{3}} \dot{x}_{3} \\
\frac{\partial s_{b}}{\partial x_{1}} \dot{x}_{1}+\frac{\partial s_{b}}{\partial x_{2}} \dot{x}_{2}+\frac{\partial s_{b}}{\partial x_{3}} \dot{x}_{3}
\end{array}\right]_{\mathbf{u}=\mathbf{u}_{\mathrm{eq}}} \\
& =\left[\begin{array}{l}
\frac{\partial s_{p}}{\partial x_{1}} \dot{x}_{1} \\
\frac{\partial s_{b}}{\partial x_{3}} \dot{x}_{3}
\end{array}\right]_{\mathbf{u}=\mathbf{u}_{\mathrm{eq}}}=\left[\begin{array}{l}
0 \\
0
\end{array}\right] .
\end{aligned}
$$

The equivalent control is then derived:

$$
\mathbf{u}_{\mathrm{eq}}=\left[\begin{array}{l}
u_{\mathrm{peq}} \\
u_{b \mathrm{eq}}
\end{array}\right]=\left[\begin{array}{c}
1-\frac{V_{p}\left(x_{1}\right)}{x_{2}} \\
\frac{V_{b}}{x_{2}}
\end{array}\right] .
$$

Since the range of duty cycle must lie in $0<\left(u_{p}, u_{b}\right)<1$, the real control signal is proposed as

$$
\mathbf{u}=\left[\begin{array}{l}
u_{p} \\
u_{b}
\end{array}\right]
$$

where $u_{p}$ and $u_{b}$ can be written as

$$
\begin{aligned}
& u_{p}= \begin{cases}0 & u_{p \text { eq }}+k_{p} s_{p}<0 \\
u_{p \text { eq }}+k_{p} s_{p} & 0<u_{\text {peq }}+k_{p} s_{p}<1 \\
1 & 1<u_{\text {peq }}+k_{p} s_{p}\end{cases} \\
& u_{b}= \begin{cases}0 & u_{\text {beq }}+k_{b} \operatorname{Sat}\left(\frac{s_{b}}{\phi}\right)<0 \\
u_{b e \mathrm{q}}+k_{b} \operatorname{Sat}\left(\frac{s_{b}}{\phi}\right) & 0<u_{b \mathrm{eq}}+k_{b} \operatorname{Sat}\left(\frac{s_{b}}{\phi}\right)<1 \\
1 & 1<u_{b \mathrm{eq}}+k_{b} \operatorname{Sat}\left(\frac{s_{b}}{\phi}\right)\end{cases}
\end{aligned}
$$

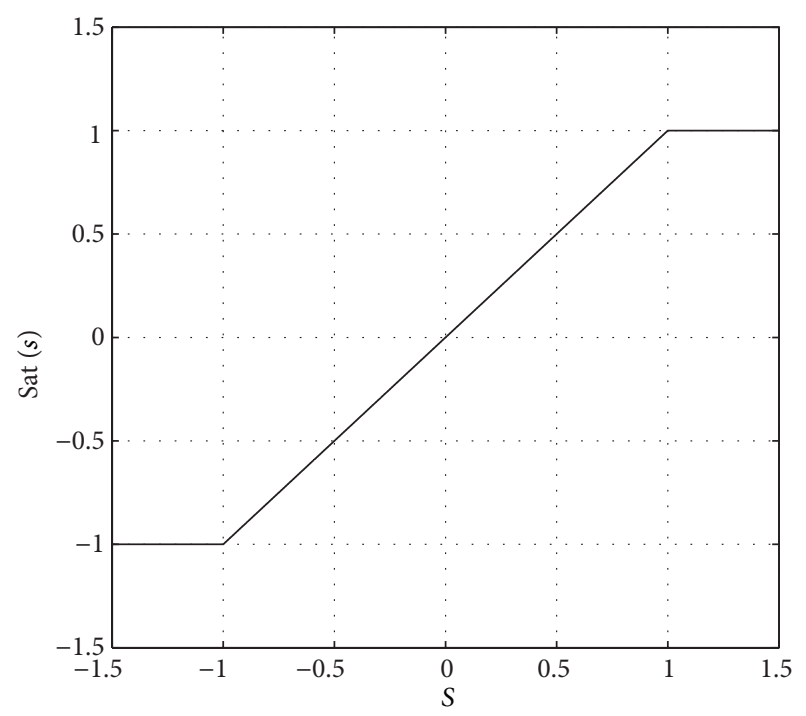

Figure 6: Saturation function.

where $k_{p}$ and $k_{b}$ are constant coefficients and are determined by trial and error method by using computer simulations, Sat $(s)$ is the saturation function which is shown in Figure 6, and $\phi$ is a small constant and is selected for chattering avoidance [16].

The existence of the approaching mode of the proposed sliding function $\mathbf{s}$ is provided. A Lyapunov function is defined as

$$
v=v_{M}+v_{R}
$$

where $v_{M}$ and $v_{R}$ are positive definite terms and defined as

$$
v_{M}=\frac{1}{2} s_{p}^{2}, \quad v_{R}=\frac{L_{b}}{2} s_{b}^{2} .
$$

The time derivative of $v$ can be written as

$$
\dot{v}=\dot{v}_{M}+\dot{v}_{R} .
$$


The achievability of $\mathbf{s}=\mathbf{0}$ will be obtained by $\dot{v}<0$. It can be shown that both $\dot{v}_{M}$ and $\dot{v}_{R}$ are negative definite. $\dot{v}_{R}$ can be written as follows:

$$
\dot{v}_{R}=s_{b}\left(V_{b}-x_{2} u_{b}\right) .
$$

Three cases should be examined for the fulfillment of $\dot{v}_{R}<0$.

$$
\text { For } \mathbf{0}<\mathbf{u}_{\mathbf{b}}<\mathbf{1}
$$

$$
\dot{v}_{R}=-x_{2} k_{b}\left(x_{3}-x_{3 d}\right) \operatorname{sat}\left(\frac{x_{3}-x_{3 d}}{\phi}\right)<0 .
$$

Since $\left(x_{3}-x_{3 d}\right)$ always has the same sign of sat $\left(\left(x_{3}-x_{3 d}\right) / \phi\right)$ and $x_{2} k_{b}>0$, the sign of (19) is negative definite.

For $\mathbf{u}_{\mathbf{b}}=1$

$$
\dot{v}_{R}=s_{b}\left(V_{b}-x_{2}\right)<0 .
$$

In this case, the load voltage $\left(x_{2}\right)$ is higher than the battery voltage $\left(V_{b}\right)$ and $s_{b}>0$. From (20) it results $\dot{v}_{R}<0$.

For $\mathbf{u}_{\mathbf{b}}=\mathbf{0}$

$$
\dot{v}_{R}=s_{b} V_{b}<0 .
$$

In this case, $s_{b}<0$ is obtained and $\dot{v}_{R}<0$.

From the discussion above, $\dot{v}_{R}<0$ is obtained.

$\dot{v}_{p}$ can also be written as

$$
\dot{v}_{M}=s_{p} \dot{s}_{p}
$$

The time derivative of $s_{p}$ can be written as

$$
\dot{s}_{p}=\left(3 \frac{\partial R_{p}}{\partial x_{1}}+x_{1} \frac{\partial^{2} R_{p}}{\partial x_{1}^{2}}\right) \frac{\left(v_{p}\left(x_{1}\right)-x_{2}+x_{2} u_{p}\right)}{L_{p}} .
$$

Replacing $R_{p}$ by the definition of $R_{p}=V_{p} / I_{p}$,

$$
\begin{aligned}
& \frac{\partial R_{p}}{\partial x_{1}}=\frac{\partial}{\partial x_{1}}\left[\frac{V_{p}}{x_{1}}\right]=\frac{1}{x_{1}} \frac{\partial V_{p}}{\partial x_{1}}-\frac{V_{p}}{x_{1}^{2}}, \\
& \frac{\partial^{2} R_{p}}{\partial x_{1}^{2}}=\frac{1}{x_{1}} \frac{\partial^{2} V_{p}}{\partial x_{1}^{2}}-\frac{2}{x_{1}^{2}} \frac{\partial V_{p}}{\partial x_{1}}+\frac{2 V_{p}}{x_{1}^{3}} .
\end{aligned}
$$

By (1), the following equations will be obtained:

$$
\begin{aligned}
& \frac{\partial V_{p}\left(x_{1}\right)}{\partial x_{1}}=-\frac{k_{b} T A}{q} \frac{i_{0}}{i_{\mathrm{ph}}+i_{0}-x_{1}}-r_{p}<0, \\
& \frac{\partial^{2} V_{p}\left(x_{1}\right)}{\partial x_{1}^{2}}=-\frac{k_{b} T A}{q} \frac{i_{0}}{\left(i_{\mathrm{ph}}+i_{0}-x_{1}\right)^{2}}<0 .
\end{aligned}
$$

Substituting (25) into (23) yields

$$
\begin{aligned}
\frac{\partial s_{p}}{\partial x_{1}} & =3 \frac{\partial R_{p}}{\partial I_{p}}+I_{p} \frac{\partial^{2} R_{p}}{\partial I_{p}^{2}} \\
& =\frac{\left(\partial v_{p}\left(x_{1}\right) / \partial x_{1}\right)}{x_{1}}+\frac{\partial^{2} v_{p}\left(x_{1}\right)}{\partial x_{1}^{2}}-\frac{v_{p}}{x_{1}^{2}}<0
\end{aligned}
$$

According to the result of $(25)$ and $\left(V_{p}, x_{1}\right)>0$, the sign of (26) is negative definite. The achievability of $\dot{v}_{p}<0$ will be obtained by $s_{p} \dot{s}_{p}<0$ for all $u_{p}$ discussed as follows.

For $\mathbf{0}<\mathbf{u}_{\mathbf{p}}<\mathbf{1}$

$$
\begin{aligned}
\dot{x}_{1} & =\frac{\left(v_{p}\left(x_{1}\right)-x_{2}\left(1-u_{p \mathrm{eq}}-k_{p} s_{p}\right)\right)}{L_{P}} \\
& =\frac{x_{2} k_{p} s_{p}}{L_{p}} .
\end{aligned}
$$

Based on the result of (26) and (27), $\dot{s}_{p}$ always has inverse sign of $s_{p}$. Therefore, $s_{p} \dot{s}_{p}<0$ is obtained for $0<u_{p}<1$.

For $\mathbf{u}_{\mathbf{p}}=\mathbf{1}$

$$
\dot{x}_{1}=\frac{V_{p}\left(x_{1}\right)}{L_{p}}>0 \text {. }
$$

By (26) and (28), $\dot{s}_{p}<0$ with $u_{p}=1$, two cases should be examined for the fulfillment of $s_{p} \dot{s}_{p}<0$.

(a) $u_{\text {peq }}=1$.

If $u_{p \text { eq }}=1$, it implies that $V_{p}\left(x_{1}\right)=0$ which means $s_{p}$ is negative for this case. Therefore, $u_{p e q}+k_{p} s_{p}$ will be less than 1 , which contradicts to the assumption of $u_{p}=1$.

(b) $u_{\text {peq }}<1$ and $u_{\text {peq }}+k_{p} s_{p} \geq 1$.

If $u_{\text {peq }}<1$, but $u_{\text {peq }}+k_{p} s_{p} \geq 1$, it implies that $s_{p}>0$ and $s_{p} \dot{s}_{p}<0$.

It conclude that $s_{p} \dot{s}_{p}<0$ for $u_{p}=1$.

For $\mathbf{u}_{\mathbf{p}}=\mathbf{0}$

$$
\dot{x}_{1}=\frac{\left(V_{p}\left(x_{1}\right)-x_{2}\right)}{L_{p}} \text {. }
$$

In this case load voltage $\left(x_{2}\right)$ is higher than the PV voltage $\left(V_{p}\left(x_{1}\right)\right)$. From (26) and (29), it results that $\dot{s}_{p}>0$. Two cases for $u_{p}=0$ are examined as follows.

$$
\text { (a) } u_{\text {peq }}=0 \text {. }
$$

$u_{\text {peq }}=0$ implies $V_{p}\left(x_{1}\right)=x_{2}$, which corresponding to the situation that the PV array is directly connected to the load and operates in the region $s_{p}>0$. As the results $u_{p}>0$ and it contradicts to the assumption of $u_{p}=0$.

(b) $u_{\text {peq }}>0$ and $u_{\text {peq }}+k_{p} s_{p} \leq 0$.

In this case, $s_{p}<0$ is obtained and $s_{p} \dot{s}_{p}<0$.

It concludes that $s_{p} \dot{s}_{p}<0$ for $u_{p}=0$.

From the discussion above, the stability of the system can be guaranteed using the proposed control law (14).

\section{Passivity Based Control}

In this study, Euler Lagrange-Passivity based control (EL$\mathrm{PBC}$ ) approach [13] is provided to compare the results with those of the proposed sliding mode controller responses. The design of the passivity based (PB) controller is based on the 
TABle 1: System specification.

\begin{tabular}{|c|c|c|c|c|c|}
\hline \multirow{2}{*}{ PV } & Model & Equivalent resistance & Maximum power & Open circuit voltage & Short circuit current \\
\hline & SM-55 & $0.03(\Omega)$ & $55(\mathrm{~W})$ & $21.7(\mathrm{~V})$ & $3.8(\mathrm{~A})$ \\
\hline \multirow{2}{*}{ Battery } & \multicolumn{2}{|c|}{ Open circuit voltage } & \multicolumn{3}{|c|}{ Equivalent resistance } \\
\hline & \multicolumn{2}{|r|}{$9(\mathrm{~V})$} & \multicolumn{3}{|c|}{$0.08(\Omega)$} \\
\hline \multirow{2}{*}{$\mathrm{DC} / \mathrm{DC}$} & & $L_{p}$ & $C$ & \multicolumn{2}{|c|}{$L_{b}$} \\
\hline & & $5(\mathrm{mH})$ & $500(\mu \mathrm{f})$ & \multicolumn{2}{|c|}{$10(\mathrm{mH})$} \\
\hline
\end{tabular}
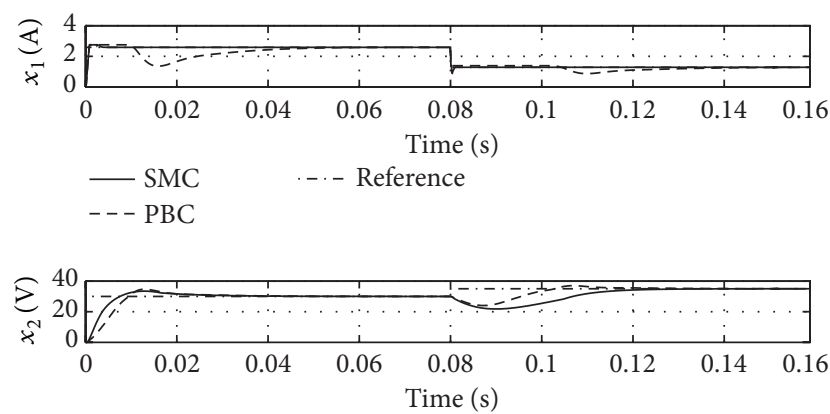

- $\mathrm{SMC} \quad \cdot-\cdot-$ Reference

$---\mathrm{PBC}$

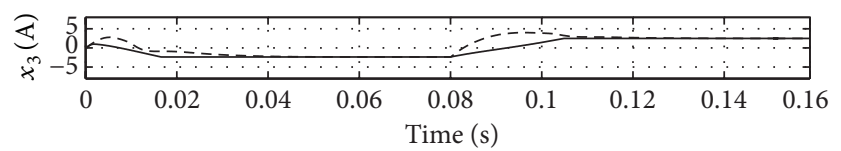

- SMC

$---\mathrm{PBC}$

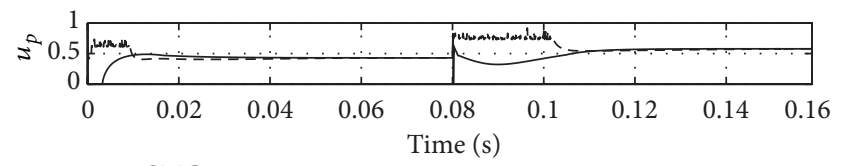

$-\mathrm{SMC}$

$---\mathrm{PBC}$

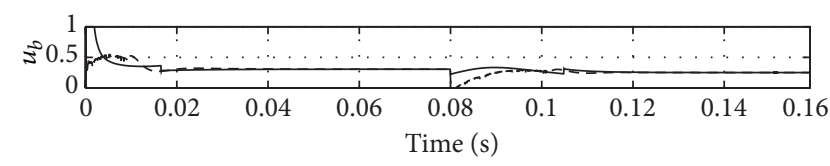

- SMC

$---\mathrm{PBC}$

FIGURE 7: State variables and control signals.

Euler Lagrange model of the converters. The PBC control signals which proposed in [13] are shown in

$$
\begin{gathered}
u_{p}=1-\frac{1}{x_{2 d}}\left(V_{p}\left(x_{1}\right)+r_{a 1}\left(x_{1}-x_{1 d}\right)\right), \\
u_{b}=\frac{1}{x_{2 d}}\left(V_{b}\left(x_{3}\right)+r_{a 2}\left(x_{3}-x_{3 d}\right)\right),
\end{gathered}
$$

where $x_{1 d}$ is the reference current and needs to be determined by MPPT algorithms, $x_{3 d}$ is the desired battery current and can be described by (9), $x_{2 d}$ is the reference of the load voltage. $\left(r_{a 1}, r_{a 2}\right)>0$ are design parameters (see [13] for more details). Passivity based control approach which is introduced in [13], required reference current $x_{1 d}$ for control

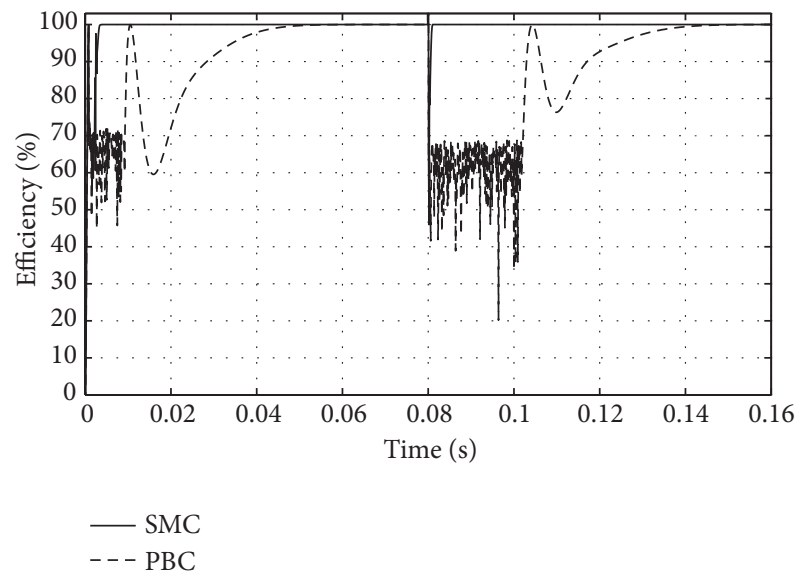

Figure 8: Efficiency.

TABLE 2: Parameters variations.

\begin{tabular}{lcc}
\hline Parameters & 0 to $79(\mathrm{~ms})$ & 80 to $160(\mathrm{~ms})$ \\
\hline Load resistance $(R)$ & $40(\mathrm{ohms})$ & $30(\mathrm{ohms})$ \\
Reference dc voltage $\left(x_{2 d}\right)$ & $30(\mathrm{v})$ & $35(\mathrm{v})$ \\
PV temperature & $290(\mathrm{k})$ & $310(\mathrm{k})$ \\
PV irradiance level & $800\left(\mathrm{w} / \mathrm{m}^{2}\right)$ & $400\left(\mathrm{w} / \mathrm{m}^{2}\right)$ \\
\hline
\end{tabular}

law synthesis and may lead to a lack of robustness to operation conditions.

\section{Simulation}

MATLAB environment is used to investigate the performance of the SMC on the proposed satellite EPS. PBC is provided to compare the results with those of proposed SMC responses. The simulation investigates four system characteristics: robustness against irradiance, temperature, load resistance, and load voltage reference changes. Unlike SMC, PBC approach required reference current $\left(x_{1 d}\right)$ for control law synthesis which comes from $\mathrm{P} \& \mathrm{O}$ algorithm [13]. It is assumed that optimal reference current $\left(x_{1 d}\right)$ is available to PBC. The parameters of the components are chosen to deliver maximum $55 \mathrm{~W}$ of power generated by SM-55 and battery. The specification of the system is tabulated in Table 1.

According to Table 2, two step changes applied to Load resistance, load voltage reference, irradiance level, and PV array temperature at $t=0$ and $t=80(\mathrm{~ms})$.

Figure 7 presents the state variables and control signals. PV array current $\left(x_{1}\right)$ based on the proposed controllers 

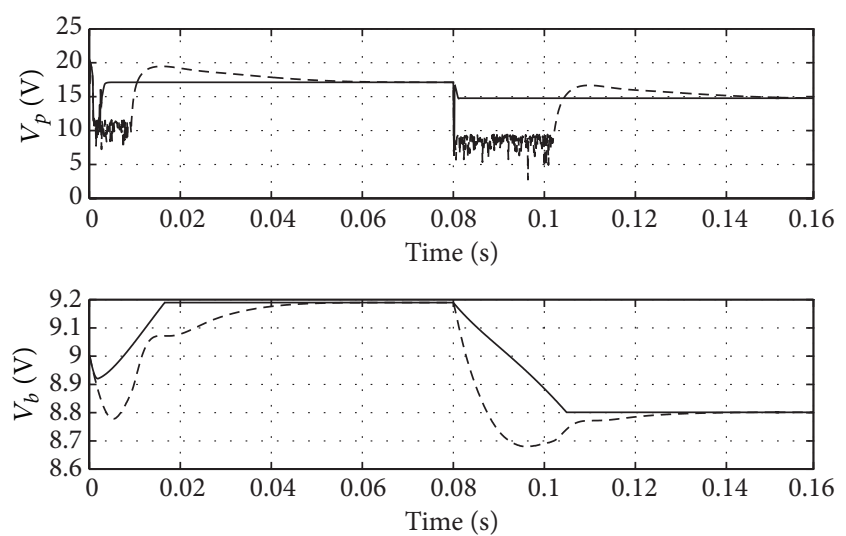

- SMC

$---\mathrm{PBC}$

FIGURE 9: PV and battery voltage.
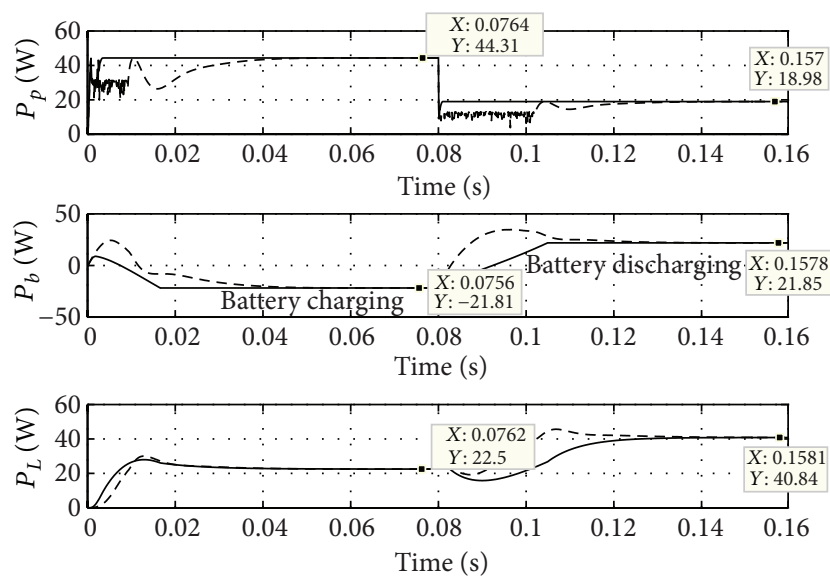

- SMC

$---\mathrm{PBC}$

FIGURE 10: PV power, battery power and load power.

has faster response with zero steady state error. The load voltage $\left(x_{2}\right)$ tracks the voltage reference $\left(x_{2 d}\right)$ well, with low overshoot, short settling time and zero steady-state error. Figure 8 shows the efficiency of the both control approaches. As illustrated in the figure, both approaches have 100\% steady state efficiency, but SMC has better transient efficiency. Unlike the SMC, the PBC approach needs optimal reference current which comes from external MPPT algorithms.

Figure 9 shows the PV array and battery voltage. Figure 10 shows PV array power, battery power, and load power. As illustrated, the proposed SMC has better transient response and charges and discharges the battery efficiently.

\section{Results}

In this paper, a state space averaging model of a satellite electrical power system (EPS) with a PV array as the main source, a battery storage as the secondary source and interfacing DC/DC converters has been presented. Subsequently, sliding mode controller has been designed to control the interfacing
DC/DC converters. To investigate the validity of the proposed system, a passivity based controller was provided. Unlike $\mathrm{PBC}$, the proposed system does not require reference current for control law synthesis. Simulation results show that both approaches have zero steady state error. But the proposed control approach has better transient response and does not require external MPPT reference current. Moreover, the aforementioned results demonstrate the robustness of the proposed control approach during the load resistance, battery voltage, solar irradiance, PV array temperature, and load voltage reference changes.

\section{References}

[1] M. A. Kaya and M. K. Bayrakceken, "Complete electrical model and simulation of a medium size satellite," in Proceedings of the 5th International Conference on Recent Advances in Space Technologies (RAST '11), pp. 522-525, Istanbul, Turkey, June 2011.

[2] C. C. Chu and C. L. Chen, "Robust maximum power point tracking method for photovoltaic cells: a sliding mode control approach," Solar Energy, vol. 83, no. 8, pp. 1370-1378, 2009.

[3] H. El Fadil and F. Giri, "Climatic sensorless maximum power point tracking in PV generation systems," Control Engineering Practice, vol. 19, no. 5, pp. 513-521, 2011.

[4] Syafaruddin, E. Karatepe, and T. Hiyama, "Performance enhancement of photovoltaic array through string and central based MPPT system under non-uniform irradiance conditions," Energy Conversion and Management, vol. 62, pp. 131-140, 2012.

[5] K. Ishaque, Z. Salam, A. Shamsudin, and M. Amjad, "A direct control based maximum power point tracking metystem under partial shading conditions using particle swarm optimization algorithm," Applied Energy, vol. 99, pp. 414-422, 2012.

[6] K. Ishaque, Z. Salam, M. Amjad, and S. Mekhilef, "An improved particle swarm optimization (PSO)-based MPPT for PV with reduced steady-state oscillation," IEEE Transactions on Power Electronics, vol. 27, no. 8, pp. 3627-3638, 2012.

[7] M. M. Algazar, H. Al-Monier, H. A. El-Halim, and M. E. E. K. Salem, "Maximum power point tracking using fuzzy logic control," International Journal of Electrical Power and Energy Systems, vol. 39, no. 1, pp. 21-28, 2012.

[8] L. Zhou, Y. Chen, Q. Liu, and J. Wu, "Maximum power point tracking (MPPT) control of a photovoltaic system based on dual carrier chaotic search," Journal of Control Theory and Applications, vol. 10, no. 2, pp. 244-250, 2012.

[9] H. T. Yau, Q. C. Liang, and C. T. Hsieh, "Maximum power point tracking and optimal Li-ion battery charging control for photovoltaic charging system," Computers and Mathematics with Applications, vol. 64, no. 5, pp. 822-832, 2012.

[10] M. A. G. de Brito, L. Galotto, L. P. Sampaio, G. de Azevedo e Melo, and C. A. Canesin, "Evaluation of the main MPPT techniques for photovoltaic applications," IEEE Transactions on Industrial Electronics, vol. 60, no. 3, pp. 1156-1167, 2013.

[11] N. Onat, "Recent developments in maximum power point tracking technologies for photovoltaic systems," International Journal of Photoenergy, vol. 2010, Article ID 245316, 11 pages, 2010.

[12] W. Xiao, A. Elnosh, V. Khadkikar, and H. Zeineldin, "Overview of maximum power point tracking technologies for photovoltaic power systems," in Proceedings of the 37th Annual 
Conference of the IEEE Industrial Electronics Society (IECON '11), pp. 3900-3905, Melbourne, Australia, November 2011.

[13] A. Tofighi and M. Kalantar, "Power management of PV/battery hybrid power source via passivity-based control," Renewable Energy, vol. 36, no. 9, pp. 2440-2450, 2011.

[14] V. I. Utkin, J. Guldner, and J. X. Shi, Sliding Mode Control in ElectroMechanical Systems, Taylor \& Francis, London, UK, 2008.

[15] F. Bilalovic, O. Music, and A. Sabanovic, "Buck converter regulator operating in the sliding mode," in Proceedings of the 7th Power Conversion International Conference, pp. 331-340, 1983.

[16] J. J. E. Slotine and W. Li, Applied Nonlinear Control, Prentice Hall, New York, NY, USA, 1991.

[17] P. Mattavelli, L. Rossetto, and G. Spiazzi, "Small-signal analysis of DC-DC converters with sliding mode control," IEEE Transactions on Power Electronics, vol. 12, no. 1, pp. 96-102, 1997.

[18] R. Ortega, J. A. Loría Perez, P. J. Nicklasson, and H. J. Sira-Ramirez, Passivity-Based Control of Euler-Lagrange Systems: Mechanical, Electrical and Electromechanical Applications, Springer, New York, NY, USA, 1998.

[19] B. Lin, "Conceptual design and modeling of a fuel cell scooter for urban Asia," in Mechanical and Aerospace Engineering, Princeton University, Princeton, NJ, USA, 1999.

[20] P. T. Krein, J. Bentsman, R. M. Bass, and B. L. Lesieutre, "On the use of averaging for the analysis of power electronic systems," IEEE Transactions on Power Electronics, vol. 5, no. 2, pp. 182190, 1989. 

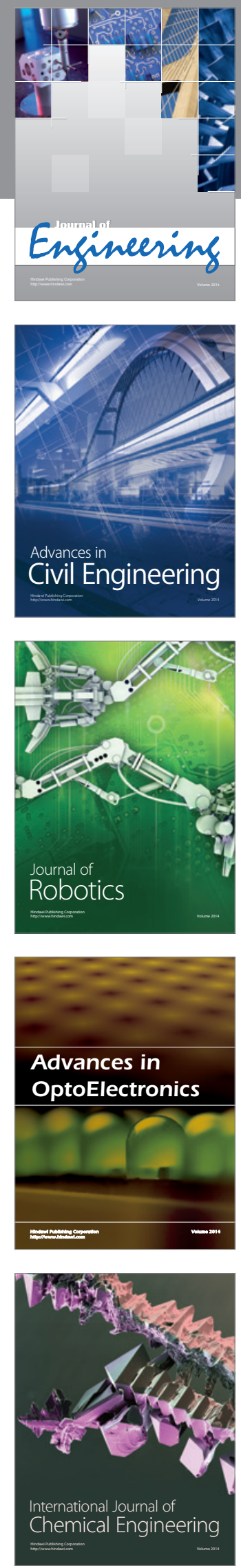

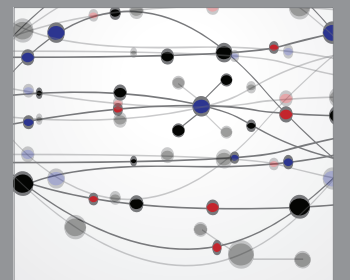

The Scientific World Journal
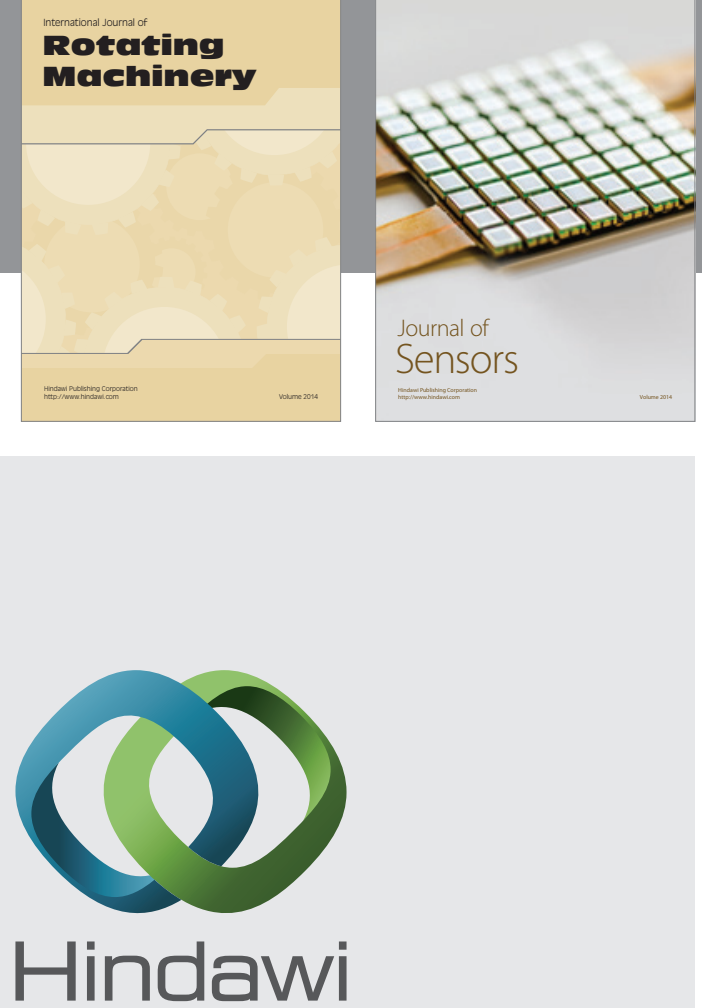

Submit your manuscripts at http://www.hindawi.com
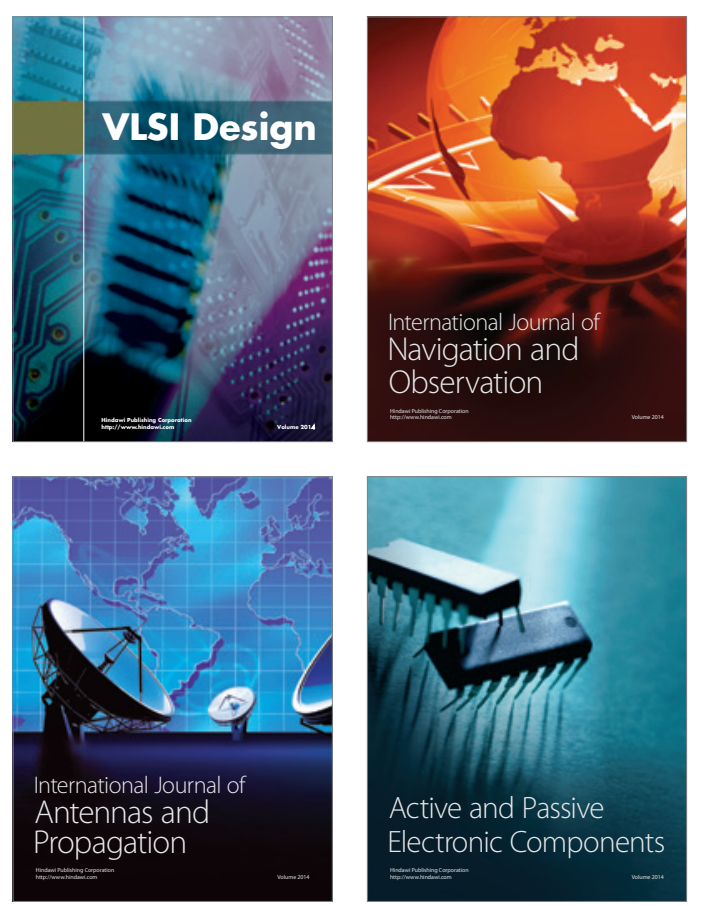
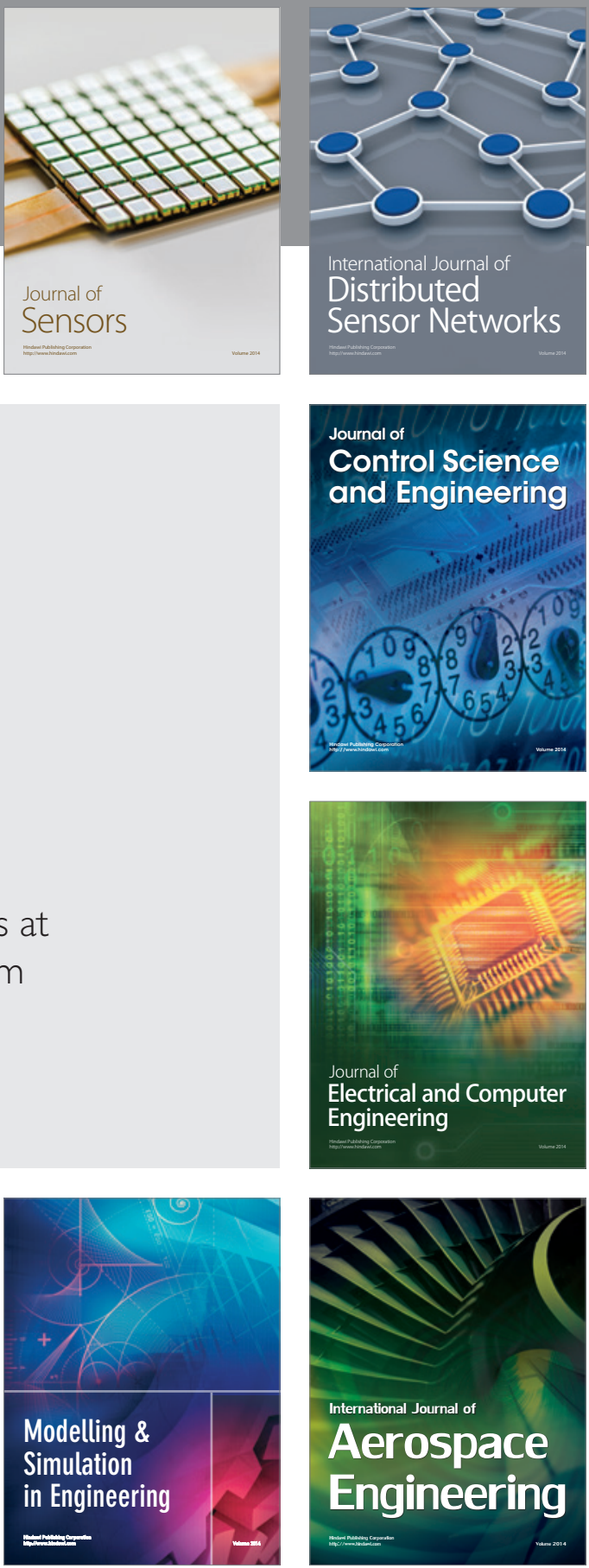

Journal of

Control Science

and Engineering
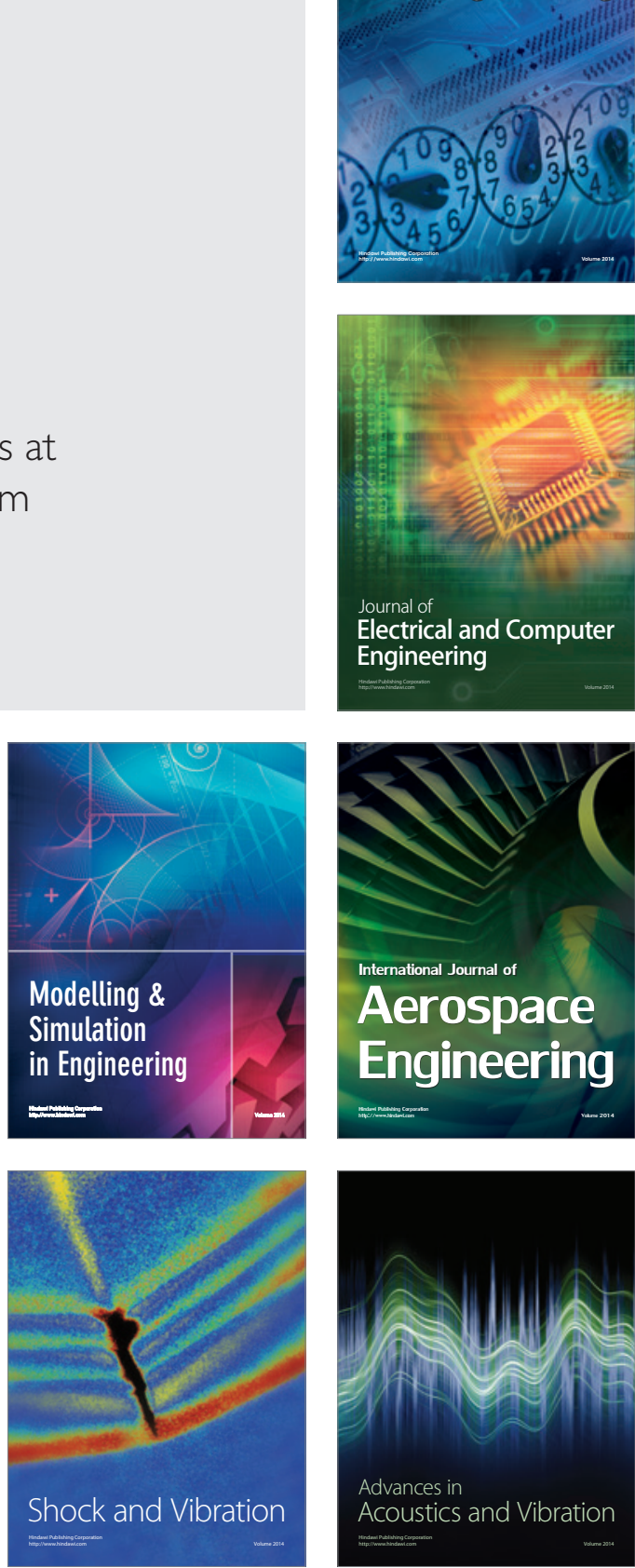